\title{
Cytosolic DNA sensor-initiated innate immune responses in mouse ovarian granulosa cells
}

\author{
Keqin Yan ${ }^{1}$, Dingqing Feng ${ }^{1}$, Jing Liang ${ }^{1}$, Qing Wang ${ }^{2}$, Lin Deng ${ }^{1}$, Xiao Zhang ${ }^{1}$, Bin Ling ${ }^{1}$ \\ and Daishu Han² \\ ${ }^{1}$ Department of Obstetrics and Gynecology, China-Japan Friendship Hospital, Beijing, China and ${ }^{2}$ Institute of Basic \\ Medical Sciences, Chinese Academy of Medical Sciences, School of Basic Medicine, Peking Union Medical College, \\ Beijing, China \\ Correspondence should be addressed to B Ling or D Han; Email: lingbin.ling@vip.sina.com or dshan@ibms.pumc.edu.cn
}

\begin{abstract}
Viral infections of the ovary may perturb ovarian functions. However, the mechanisms underlying innate immune responses in the ovary are poorly understood. The present study demonstrates that cytosolic viral DNA sensor signaling initiates the innate immune response in mouse ovarian granulosa cells and affects endocrine function. The cytosolic DNA sensors p204 and cGAS and their common signaling adaptor stimulator of interferon (IFN) genes (STING) were constitutively expressed in granulosa cells. Transfection with VACV70, a synthetic vaccinia virus (VACV) DNA analog, induced the expression of type I interferons (IFNA/B) and major inflammatory cytokines (TNFA and IL6) through IRF3 and NF- $\kappa$ B activation respectively. Moreover, several IFN-inducible antiviral proteins, including 2', $\mathbf{5}^{\prime}$-oligoadenylate synthetase, IFN-stimulating gene 15 and Mx GTPase 1, were also induced by VACV70 transfection. The innate immune responses in granulosa cells were significantly reduced by the transfection of specific smallinterfering RNAs targeting p204, cGas or Sting. Notably, the VACV70-triggered innate immune responses affected steroidogenesis in vivo and in vitro. The data presented in this study describe the mechanism underlying ovarian immune responses to viral infection. Reproduction (2017) 153 821-834
\end{abstract}

\section{Introduction}

Various virus types can infect the ovary and impair ovarian functions. Vaccinia virus exhibits high tropism for the ovary and can cause ovary pathology and sterility (Zhao et al. 2011). Immunohistochemistry studies have revealed that vaccinia virus can penetrate through the theca and granulosa layers in vivo (McCart et al. 2001). Mumps virus can infect granulosa cells and induce cell apoptosis, which is associated with premature ovarian failure (Morrison et al. 1975, Wang et al. 2016). Human immunodeficiency viruses frequently infect the ovary and cause ovarian dysfunction (Cejtin et al. 2006, Ohl et al. 2010). Hepatitis B viruses can infect human oocytes and ovarian granulosa cells, which may lead to maternal-fetal transmission (Hu et al. 2011, Jin et al. 2011). However, the mechanisms underlying innate immune responses in ovarian cells and their detrimental effects on ovarian functions remain largely unknown.

Pattern recognition receptors (PRRs) recognize conserved pathogen-associated molecular patterns (PAMPs) of pathogens and initiate the innate immune response, which is the frontline of defense against invading pathogens (Kumar et al. 2011). Several subfamilies of PRRs have been identified thus far: toll-like receptors (TLRs) (Li et al. 2009), retinoic acid-inducible gene I (RIG-I)-like receptors (RLRs) (Yoneyama \& Fujita 2007), nucleotide oligomerization domain (NOD)-like receptors (NLRs) (Martinon et al. 2009) and cytosolic DNA sensors (Keating et al. 2011, Orzalli \& Knipe 2014). These PRRs can be recognized by PAMPs from diverse pathogens, such as bacteria, viruses, fungi and parasites (Kumar et al. 2011). Various PRRs, including TLRs, RLRs and DNA sensors, can recognize viral nucleic acids and initiate the innate immune response (Barbalat et al. 2011). We recently demonstrated that TLR3, RIG-I and melanoma differentiation-associated gene 5 (MDA5) initiate innate immune responses in ovarian cells and perturb ovarian functions (Yan et al. 2013, 2014, 2015). However, the cytosolic viral DNA sensor-initiated innate immune response in the ovary has yet to be investigated. Several cytosolic DNA sensors, including DNA-dependent activator of interferon regulatory factors (DAI), RNA polymerase III (Pol III), cGMP-AMP synthase (CGAS) and interferon (IFN)-inducible protein 16 (p204 in mouse), initiate innate immune responses to viral DNA challenge. DAl was initially recognized as a cytosolic DNA sensor that initiates innate immune responses (Takaoka et al. 2007). Pol III can be considered a DNA sensor because it can transcribe DNA to RNA and activate retinoic acid-inducible gene I-like receptors 
(Chiu et al. 2009). IFI16 is a DNA-binding protein and mediates DNA virus-triggered innate immune responses (Veeranki \& Choubey 2012). cGAS has been identified as a cytosolic DNA sensor that can trigger innate immune response signaling (Sun et al. 2013). The stimulator of IFN genes (STING) is a common adaptor of DNA sensormediated signaling (Ishikawa et al. 2009).

Cytosolic DNA sensor signaling can be initiated by viral DNA and result in the activation of nuclear factor kappa $\mathrm{B}(\mathrm{NF}-\mathrm{\kappa} \mathrm{B})$ and interferon regulatory factor 3 (IRF3), thereby inducing the expression of proinflammatory cytokines and type I interferons (IFNA/B) respectively (Wang et al. 2008, Unterholzner et al. 2010). Type I IFN production is the primary antiviral response and subsequently induces a broad spectrum of antiviral proteins in the infected cells and facilitates antiviral adaptive immunity against invading viruses (Randall \& Goodbourn 2008, Desmet \& Ishii 2012). The antiviral proteins IFN-stimulated gene 15 (ISG15), 2',5'-oligoadenylate synthetase (OAS1), doublestranded RNA (dsRNA)-activated protein kinase (PKR) and Mx GTPase 1 (MX1) can amplify antiviral signaling, degrade viral RNA, inhibit viral protein translation and block viral mRNA transcription respectively (Medzhitov 2007, Sadler \& Williams 2008).

The ovarian follicle, in which numerous granulosa cells encompass an oocyte, is devoid of immune cells (Petrovska et al. 1996). It is reasonable to speculate that granulosa cells possess innate defense capabilities against invading pathogens (Sheldon \& Bromfield 2011). Increasing evidence has shown that various PRRs are expressed and functional in ovarian cells. TLR4 is expressed in human granulosa cells from in vitro fertilization (Serke et al. 2009). TLR signaling pathways have recently been analyzed in human granulosa cell lines and in bovine and hen primary granulosa cells (Woods et al. 2009, Bromfield \& Sheldon 2011, Price et al. 2012). TLR1-9 is expressed in normal human ovaries and in ovarian cancer (Zhou et al. 2009). Lipopolysaccharides initiate innate immune responses in bovine granulosa cells, perturbing estradiol synthesis and oocyte meiotic progression through TLR4 signaling (Herath et al. 2007, Bromfield \& Sheldon 2011). TLR2 and TLR4 regulate ovulation and fertilization in mice (Shimada et al. 2006, 2008, Liu et al. 2008). A recent study showed that virus infection initiated innate immune responses through the activation of RIG-I and MDA5 in the ovaries of shelducks (Fu et al. 2016). We recently demonstrated that viral dsRNA sensors, including TLR3, MDA5 and RIG-I, initiated innate immune responses in mouse ovarian granulosa and stromal cells after challenge with dsRNA, which inhibited the steroidogenesis of the ovary (Yan et al. 2013, 2014).

Although DNA viruses, such as vaccinia virus and hepatitis B virus, can infect the ovary, DNA sensorinitiated innate immune responses in ovarian cells are yet to be investigated. The present study aims to elucidate the roles of cytosolic DNA sensors in initiating innate immune responses in mouse ovarian granulosa cells to vaccinia viral DNA challenge. VACV70 is a double-stranded $70 \mathrm{bp}$ oligonucleotide containing vaccinia virus DNA motifs, which can potently trigger cytosolic DNA sensor signaling mimicking vaccinia virus (Unterholzner et al. 2010). We demonstrate that VACV70 triggers innate immune responses by the activation of p204 and cGAS in mouse ovarian granulosa cells.

\section{Materials and methods}

\section{Animals}

C57BL/6J mice were obtained from the Laboratory Animal Center, Chinese Academy of Medical Sciences (Beijing, China). The mice were bred under specific pathogen-free conditions with standard nutrition (food and water ad libitum) and light cycles (12 h light; $12 \mathrm{~h}$ darkness). Three- to five-week-old female mice were used in this study. The mice were handled in compliance with the Guidelines for the Care and Use of Laboratory Animals established by the Chinese Council on Animal Care. All experimental protocols were reviewed and approved by the Institutional Animal Care and Use Committee of Institute of Basic Medical Sciences, Chinese Academy of Medical Sciences (the permit number: SCXK (jing) 2007-0001).

\section{Antibodies and major reagents}

The TNFA-neutralizing antibody (ab176489) was purchased from Abcam. The other antibodies used in this study are listed in Table 1. VACV70 (t|rl-vav70n), BX795 (t|r-bx7) and BAY117082 (t|rl-b82) were purchased from InvivoGen (San Diego, CA, USA). Small-interfering RNAs (siRNAs) targeting mouse p204 (sc-40700), cGas (sc-95512) and Sting (sc-154411) and the control siRNA (sc-37007) were purchased from Santa Cruz Biotechnology.

\section{Isolation and culture of granulosa cells}

Mouse ovarian granulosa cells were isolated based on previously described procedures with modifications (Vanderhyden et al. 1992). Briefly, three-week-old female mice were intraperitoneally injected with $5 \mathrm{IU}$ pregnant mare serum gonadotropin (Beijing Chief-East Tech Co., Beijing, China). At $45 \mathrm{~h}$ after injection, the follicles on the surface of the ovaries were punctured with a 25-gauge needle to release oocytecumulus cell complexes and clumps of mural granulosa cells. After the removal of oocytes using a mouth-operated glass fine pipette, the granulosa cells were collected and cultured in F12/DMEM (Life Technologies) supplemented with 10\% fetal calf serum (FCS, Life Technologies) and antibiotics $(100 \mathrm{U} / \mathrm{mL}$ penicillin and $100 \mathrm{mg} / \mathrm{mL}$ streptomycin).

\section{Isolation of macrophages}

Mouse macrophages were collected from peritoneal cavities based on a previously described procedure (Chong et al. 2005). Briefly, the peritoneal cavities were lavaged with $5 \mathrm{~mL}$ 
Table 1 Antibodies used in this study.

\begin{tabular}{|c|c|c|c|c|c|c|}
\hline Vendor & Antibody & Host species & Catalog number & Use & Working dilution & Conjugation \\
\hline \multirow[t]{4}{*}{ Sigma-Aldrich } & Anti- $\beta$-actin & Mouse & A5316 & WB & 1:4000 & \\
\hline & Anti-cGAS & Rabbit & SAB3500110 & WB & $1: 500$ & \\
\hline & & & & IF & $1: 100$ & \\
\hline & & & & $\mathrm{IHC}$ & 1:100 & \\
\hline \multirow[t]{12}{*}{ Abcam } & Anti-p204 & Rabbit & ab104409 & WB & 1:1000 & \\
\hline & & & & IF & 1:200 & \\
\hline & & & & IHC & 1:200 & \\
\hline & Anti-STING & Rabbit & ab179775 & WB & 1:1000 & \\
\hline & Anti-DAI & Rabbit & ab81526 & WB & 1:1000 & \\
\hline & Anti-Pol III & Rabbit & ab22236 & WB & 1:1000 & \\
\hline & Anti-OAS1 & Rabbit & ab86343 & WB & 1:1000 & \\
\hline & Anti-ISG15 & Rabbit & ab131119 & WB & $1: 500$ & \\
\hline & Anti-P450arom & Rabbit & ab18995 & WB & $1: 500$ & \\
\hline & Anti-P450SCC & Rabbit & ab175408 & WB & 1:1000 & \\
\hline & Anti-HSD3B & Rabbit & ab150384 & WB & 1:1000 & \\
\hline & Anti-STAR & Rabbit & ab58013 & WB & $1: 500$ & \\
\hline \multirow[t]{4}{*}{ Santa Cruz Biotechnology } & Anti-IRF3 & Rabbit & sc-9082 & WB & 1:1000 & \\
\hline & & & & IF & 1:200 & \\
\hline & Anti-MX1 & Rabbit & sc-50509 & WB & $1: 500$ & \\
\hline & Anti-FSHR & Goat & sc-7798 & IF & 1:200 & \\
\hline \multirow[t]{4}{*}{ Cell Signaling } & Anti-p65 & Rabbit & 4764 & WB & 1:1000 & \\
\hline & & & & IF & $1: 200$ & \\
\hline & Anti-p-p65 & Rabbit & 3031 & WB & 1:1000 & \\
\hline & Anti-p-IRF3 & Rabbit & 4947 & WB & 1:1000 & \\
\hline \multirow[t]{4}{*}{ Zhongshan Biotechnology Co., Beijing, China } & Mouse IgG & Goat & ZB-2305 & WB & 1:4000 & HRP \\
\hline & Rabbit IgG & Goat & ZB-2301 & WB & 1:4000 & HRP \\
\hline & & & & IHC & 1:200 & \\
\hline & Rabbit IgG & Goat & ZF-0311 & IF & $1: 200$ & FITC \\
\hline
\end{tabular}

FITC, fluorescein isothiocyanate; HRP, horseradish peroxidase; IF, immunofluorescence staining; IHC, immunohistochemistry; WB, Western blot.

of ice-cold $1 \times$ phosphate-buffered saline (PBS). The lavaged cells were collected by centrifugation at $250 \mathrm{~g}$ for $5 \mathrm{~min}$ at room temperature. The cells were subsequently re-suspended in RPMI-1640 medium (Life Technologies) supplemented with $10 \%$ FCS and antibiotics $(100 \mathrm{U} / \mathrm{mL}$ penicillin and $100 \mathrm{mg} / \mathrm{mL}$ streptomycin) and incubated in a humidified atmosphere with $5 \% \mathrm{CO}_{2}$ at $37^{\circ} \mathrm{C}$. After $24 \mathrm{~h}$, non-adherent cells were removed by washing with PBS. The adherent cells were determined to be macrophages with a purity of more than $95 \%$ based on immunostaining for F4/80, a marker of macrophages (Hume et al. 1984).

\section{Transfection}

Ovarian granulosa cells were seeded in 6-well plates at a density of $5 \times 10^{5}$ cells/well and cultured for $24 \mathrm{~h}$. The medium was then replaced with serum-free F12/DMEM. Two hours later, the cells were transfected with $2 \mu \mathrm{g} / \mathrm{mL}$ VACV70 using $2 \mu \mathrm{L}$ of Lipofectamine RNAiMAX Reagent (Invitrogen) according to the manufacturer's instructions. For gene silencing with siRNA, $2 \times 10^{5}$ granulosa cells per well were seeded in 6 -well plates. At $24 \mathrm{~h}$ after seeding, the cells were transfected with $100 \mathrm{nM}$ siRNA using the method described previously. After $24 \mathrm{~h}$, the cells were transfected with VACV70.

\section{Real-time quantitative RT-PCR (qRT-PCR)}

Total RNA was extracted using TRIzol reagent (Invitrogen) according to the manufacturer's instructions. After treatment with RNase-free DNase I (Invitrogen) to remove genomic DNA contamination, the RNA $(1 \mu \mathrm{g})$ was reverse transcribed into cDNA in a $20 \mu \mathrm{L}$ reaction mixture containing $2.5 \mu \mathrm{M}$ random hexamers, $2 \mu \mathrm{M}$ dNTP and $200 \mathrm{U}$ Moloney murine leukemia virus reverse transcriptase (Promega). PCR was performed in a $20 \mu \mathrm{L}$ reaction system containing $0.2 \mu \mathrm{L}$ of $\mathrm{cDNA}, 0.5 \mu \mathrm{M}$ each forward and reverse primers and $10 \mu \mathrm{L}$ of $2 \times$ Power SYBR Green PCR Master Mix (Applied Biosystems) using an ABI PRISM 7300 real-time cycler (Applied Biosystems). The mRNA levels of the target genes were normalized to $\beta$-actin using the comparative threshold cycle method described in Applied Biosystems User Bulletin No. 2 ( $\mathrm{P} / \mathrm{N}$ 4303859). The primer pairs used for PCR are listed in Table 2.

\section{Western blot analysis}

Cells or tissues were lysed using a lysis buffer (Applygen Technologies Inc., Beijing, China). The protein concentration of the lysates was determined using the bicinchoninic acid protein assay kit (Pierce Biotechnology). Equal amount of proteins $(20 \mu \mathrm{g})$ were separated on $10 \%$ SDS-PAGE gels and subsequently electrotransferred onto polyvinyl difluoride membranes (Millipore). After blocking in Tris-buffered saline (TBS, pH 7.4) containing 5\% nonfat milk for $1 \mathrm{~h}$ at room temperature, the membranes were incubated with primary antibodies overnight at $4{ }^{\circ} \mathrm{C}$. Then, the membranes were washed twice with TBS containing $0.1 \%$ Tween 20 and incubated with the appropriate horseradish peroxidase (HRP)conjugated secondary antibodies (Zhongshan Biotechnology 
Table 2 Primers used for real-time quantitative RT-PCR.

\begin{tabular}{|c|c|c|}
\hline \multirow[b]{2}{*}{ Target genes } & \multicolumn{2}{|c|}{ Primer pairs $\left(5^{\prime}-3^{\prime}\right)$} \\
\hline & Forward & Reverse \\
\hline$\beta$-Actin & GAAATAGTGCGTGACATCAAAG & TGTAGTTTCATGGATGCCACAG \\
\hline p204 & TCAGTTTCAGTAGCCACGGTAGCA & TGGTCCCAAACAAGTGATGGTGC \\
\hline Dai & GGAAGATCTACCACTCACGTC & CCTTGTTGGCAGATCATGTTG \\
\hline cGas & ACGAGAGCCGTTTTATCTCGTACCC & TGTCCGGAAGATTCACAGCATGTTT \\
\hline Pol III & TTTCCAGCAGATGCCTCTTT & ACGAGCTGCATCCTAGTGCT \\
\hline Sting & ССТAGССТСGСАСGAACTTG & CGCACAGCCTTCCAGTAGC \\
\hline Tnfa & САТСТTСТСАAАATTCGAGTGACAA & TGGGAGTAGACAAGGTACAACCC \\
\hline $1 / 6$ & GAGGATACCACTCCCCAACAGACC & AAGTGCATCATCGTTGTTCATACA \\
\hline Ifna & GACСТCCACCAGCAGCTCCAA & АСССССАССТGСТGСАТ \\
\hline Ifnb & GACGTGGGAGATGTCCTCAAC & GGTACCTTTGCACCCTCCAGTA \\
\hline$M \times 1$ & GACCATAGGGGTCTTGACCAA & AGACTTGCTCTTTCTGAAAAGCC \\
\hline Oas1 & ATTACСТCСТTCCCGACACC & САААСТССАССТССТGАТGC \\
\hline $\operatorname{lsg} 15$ & CСAGTCTCTGACTGTGAGAGC & GCATCACTGTGCTGCTGGGAC \\
\hline P450arom & CGGAGGAATGCACAGGCTCGAG & CGATGTACTTCCCAGCACAGC \\
\hline P450scC & AGGTCCTTCAATGAGATCCCTT & TCCCTGTAAATGGGGCCATAC \\
\hline$H s d 3 b$ & TATTCTCGGTTGTACGGGCAA & GTGCTACCTGTCAGTGTGACC \\
\hline Star & ATGTTCCTCGTCACGTTCAAG & CCCAGTGCTCTCCAGTTGAG \\
\hline Fshr & GGCGGCAAACCTCTGAACT & CCAGGCTGAGTCATATCATCAATATC \\
\hline
\end{tabular}

Co., Beijing, China) at room temperature for $1 \mathrm{~h}$. The HRP activity was detected using an enhanced chemiluminescence detection kit (Zhongshan Biotechnology Co.).

\section{Immunofluorescence staining and immunohistochemistry}

Cells cultured on Lab-Tek Chamber Slides (Nunc, Naperville, $\mathrm{IL}$, USA) were fixed with pre-chilled methanol at $-20^{\circ} \mathrm{C}$ for $3 \mathrm{~min}$ and subsequently permeabilized with $0.2 \%$ Triton $X-100$ in $1 \times$ PBS for 15 min. After blocking with $10 \%$ normal goat serum in PBS for $30 \mathrm{~min}$ at room temperature, the cells were incubated with primary antibodies for $1 \mathrm{~h}$ at $37^{\circ} \mathrm{C}$ in a humid chamber. Then, the cells were washed three times with PBS and incubated with the appropriate fluorescein isothiocyanate-conjugated secondary antibodies (Zhongshan Biotechnology Co.) for $30 \mathrm{~min}$ at $37^{\circ} \mathrm{C}$. Negative control cells were incubated with pre-immune rabbit serum instead of the primary antibodies. After co-staining with DAPI, the cells were mounted with a mounting solution (Vector Laboratories, Inc., Burlingame, CA, USA) for observation under a fluorescence microscope (IX-71; Olympus).

Ovaries from 5-week-old mice were used for immunohistochemistry studies according to previously described procedures (Wang et al. 2005). Briefly, after $24 \mathrm{~h}$ of fixation in Bouin's solution, the ovaries were embedded in paraffin and cut into 5 - $\mu$ m-thick sections. The sections were incubated for 15 min with $1 \times$ PBS containing $3 \% \mathrm{H}_{2} \mathrm{O}_{2}$ to inhibit endogenous peroxidase activity, soaked in citrate buffer and then microwaved at $100^{\circ} \mathrm{C}$ for $10 \mathrm{~min}$ to retrieve antigens. After blocking with 5\% normal rabbit sera in PBS for $1 \mathrm{~h}$ at room temperature, the sections were incubated with primary antibodies overnight at $4^{\circ} \mathrm{C}$. After rinsing with PBS, the sections were incubated with biotinylated secondary antibodies at room temperature for $30 \mathrm{~min}$. The streptavidinperoxidase activity was visualized using the diaminobenzidine method. Negative control sections were incubated with preimmune sera instead of the primary antibodies. The sections were counter-stained with hematoxylin and mounted with a mounting solution.

\section{Enzyme-linked immunosorbent assay (ELISA)}

The ovaries were lysed by grinding in $1 \times$ PBS and centrifuged at $800 \mathrm{~g}$ for $5 \mathrm{~min}$, and the supernatants were collected for ELISA. The granulosa cells were cultured in six-well plates at a density of $5 \times 10^{5}$ cells and then transfected with VACV70 in serum-free F12/DMEM. At $24 \mathrm{~h}$ after transfection, the concentration of cytokines in the culture medium was measured using ELISA kits according to the manufacturer's instructions. Kits for IL6 (BMS603/2), TNFA (BMS607/3) and IFNA (BMS6027) were purchased from eBioscience (San Diego, CA, USA), the kit for IFNB (42400) was purchased from R\&D Systems and kits for estradiol (582251) and testosterone (582701) were purchased from Cayman Chemical Company. The concentration detection limits of the kits for IL6, TNFA, IFNA, IFNB, estradiol and testosterone were 6.5, 3.7, 7.5, 1.0, 3.7 and $4.2 \mathrm{pg} / \mathrm{mL}$ respectively.

\section{Local injection of VACV70 into the ovarian bursa}

For the local injection of VACV70 into the ovarian bursa, fourweek-old female mice were anesthetized using pentobarbital sodium $(50 \mathrm{mg} / \mathrm{kg})$, and the ovaries were surgically exposed. One ovary was injected with a mixture of $0.2 \mu \mathrm{g}$ of VACV70 and $1 \mu \mathrm{L}$ of Lipofectamine RNAiMAX in a total volume of $10 \mu \mathrm{L}$ with $1 \times$ PBS using a 31-gauge insulin syringe through the ovarian fat into the ovarian bursa according to previously described procedures (Zhang et al. 2013). The contralateral ovary was injected with an equal volume of PBS and $1 \mu \mathrm{L}$ of Lipofectamine RNAiMAX to serve as the control.

\section{MTT assay}

Cell viability was assessed using a 3-(4,5-dimethylthiazolyl2)-2,5-diphenyltetrazolium bromide (MTT) assay kit (ATCC) 
according to the manufacturer's instructions. Briefly, granulosa cells were cultured in 96-well microplates at a density of $2 \times 10^{4}$ cells/well. After treatment with the same conditions as those for the innate immune response induction, the cells were incubated with $10 \mu \mathrm{L}$ of MTT solution for $2 \mathrm{~h}$. After the removal of the culture medium, $100 \mu \mathrm{L}$ of detergent reagent was added in each well to lyse the cells. The absorbance at $570 \mathrm{~nm}$ was recorded by a microplate reader (BioTek).

\section{Statistical analysis}

The data are presented as the mean \pm S.E.M. Student's $t$-test was used to determine the significance between treatments. A one-way ANOVA test with Bonferroni's correction was used for multiple comparisons. The data were analyzed using the statistical software SPSS, version 11.0. Values of $P<0.05$ were considered to be statistically significant.

\section{Results}

\section{Expression of cytosolic DNA sensors in mouse ovarian granulosa cells}

The purity of granulosa cells was more than 95\%, which was confirmed by examining the expression of FSHR, a marker of granulosa cells (Camp et al. 1991) (Fig. 1A). The real-time quantitative reversetranscription PCR (qRT-PCR) results showed that granulosa cells express Fshr (Fig. 1A, left panel), whereas Fshr mRNA was not detected in peritoneal macrophages from the same mice. Indirect immunofluorescence staining confirmed that FSHR protein was located in the granulosa cells (Fig. 1A, middle panel), which was not detected in macrophages (Fig. 1A, right panel). The expression of cytosolic viral DNA sensors, including p204, DAI, cGAS and Pol III, and their common adaptor STING was examined in mouse ovarian granulosa cells. Peritoneal macrophages from the same mice were used as positive controls. The real-time quantitative reverse-transcription PCR results showed that p204, cGas and Sting were expressed at comparable levels in granulosa cells and macrophages (Fig. 1B). In contrast, the DAI and Pol III mRNA levels were relatively low in granulosa cells compared with the macrophages. The protein levels of the DNA sensors were confirmed using Western blot analysis (Fig. 1C). Indirect immunofluorescence staining (Fig. 1D, upper panels) showed that p204 was distributed in both the cytoplasm and nucleus of the granulosa cells, whereas cGAS was mainly located in the cytoplasm of the granulosa cells (Fig. 1D, lower panels). Immunohistochemistry confirmed that the p204 and cGAS proteins were predominantly located in the granulosa cells (black arrows) (Fig. 1E), whereas the stromal (white arrows) and theca (black arrowheads) cells only faintly expressed these two proteins.
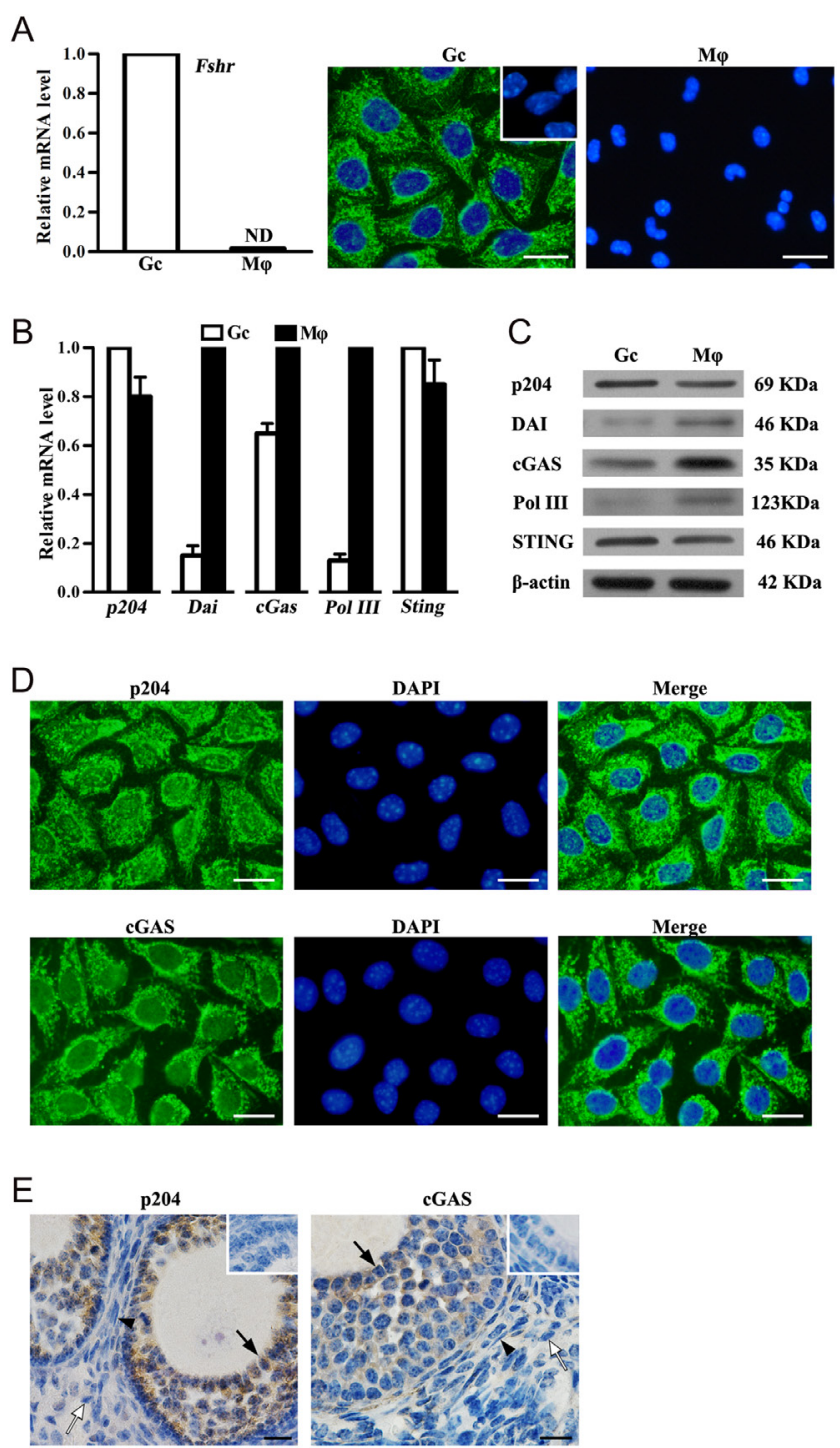

Figure 1 Expression of cytosolic DNA sensors. (A) Expression of follicle-stimulating hormone receptor (FSHR). Total RNA was extracted from mouse ovarian granulosa cells (Gc) and peritoneal macrophages $(\mathrm{M} \varphi)$ and analyzed for relative mRNA levels of Fshr by normalizing to $\beta$-actin (left panel). Immunofluorescence staining using specific antibodies against mouse FSHR was performed in Gc (middle panel) and $M \varphi$ (right panel). (B) The mRNA levels of the cytosolic DNA sensors. Total RNA was extracted from Gc and $M \varphi$. The relative mRNA levels of p204, Dai, cGas, Pol III and their common signaling adaptor Sting were determined using real-time quantitative RT-PCR by normalizing to $\beta$-actin. (C) The protein levels of the cytosolic DNA sensors and STING were determined by Western blot analysis using specific antibodies. $\beta$-Actin was used as loading control. (D) The distribution of p204 and cGAS proteins in granulosa cells. Immunofluorescence staining was performed using specific antibodies. The cells were co-stained with 4',6-diamidino-2-phenylindol. (E) The localization of p204 and cGAS in the mouse ovary. Immunohistochemistry was performed on sections of paraffin-embedded ovaries using specific antibodies. The black arrows, white arrows and black arrowheads indicate granulosa cells, stromal cells and theca cells, respectively. The insets in the upper right corners of the images represent negative controls for immunostaining. The images are representative of at least three experiments. The data represent the mean \pm S.E.M. of three experiments. Bar $=20 \mu \mathrm{m}$. 


\section{VACV70 induces innate immune responses in granulosa cells}

Cytosolic viral DNA sensors can recognize VACV70 and thereby initiate the innate immune response (Unterholzner et al. 2010). To assess the cytosolic DNA sensor functions in granulosa cells, we examined the innate immune response after transfection with $2 \mu \mathrm{g} /$ $\mathrm{mL}$ VACV70. We found that VACV70 transfection significantly upregulated the expression of p204 and cGAS at both the mRNA (Fig. 2A) and protein (Fig. 2B) levels. The mRNA levels of p204 and cGas peaked at
$18 \mathrm{~h}$ after VACV70 transfection. By contrast, Pol III, DAI and STING expressions were not changed after VACV70 transfection (data not shown). The expression of Ifna, Ifnb, I/6 and Tnfa was dramatically induced by VACV70 in a time-dependent manner (Fig. 2C). Peak mRNA levels appeared at $6 \mathrm{~h}$ after VACV70 transfection. VACV70 also induced the expression of these cytokines in a dosedependent manner (Fig. 2D). The plateaus of mRNA levels were observed after the cells were transfected with 2 and $5 \mu \mathrm{g} / \mathrm{mL}$ VACV70. Therefore, we performed in vitro experiments with $2 \mu \mathrm{g} / \mathrm{mL}$ VACV70 in this study.
A

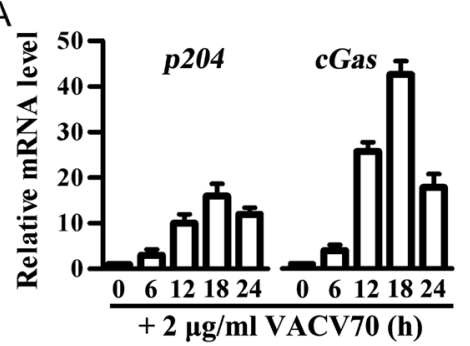

B

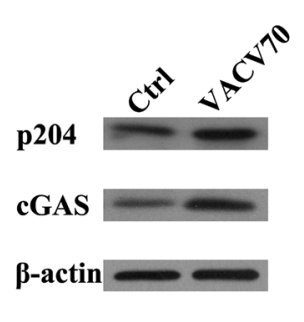

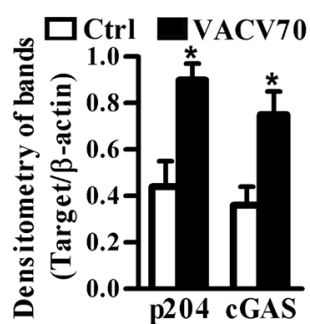

C

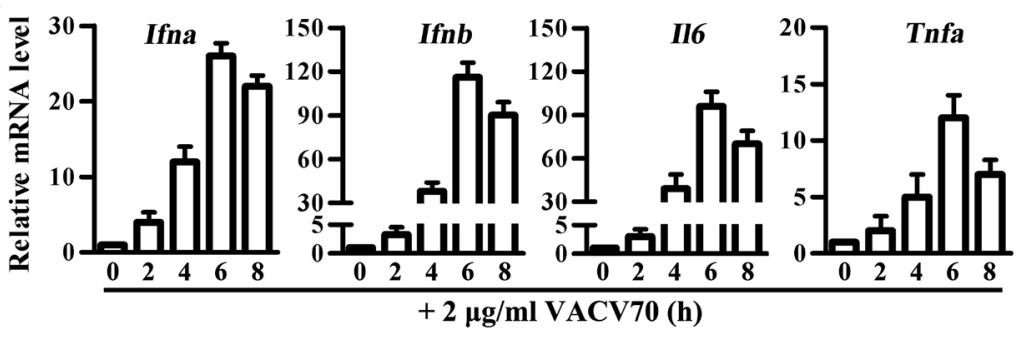

D

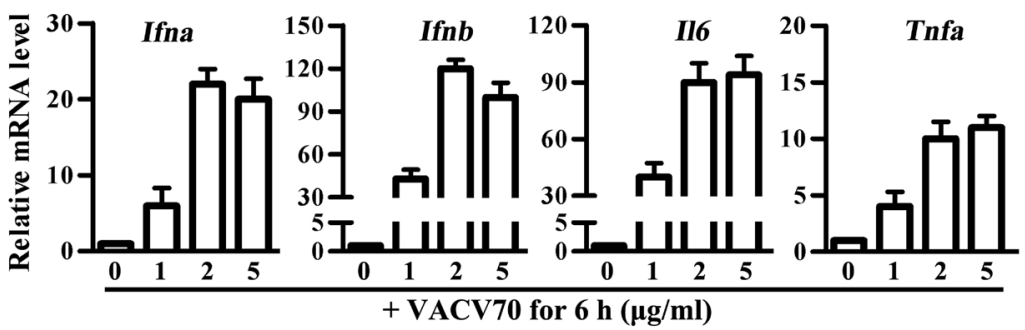

E

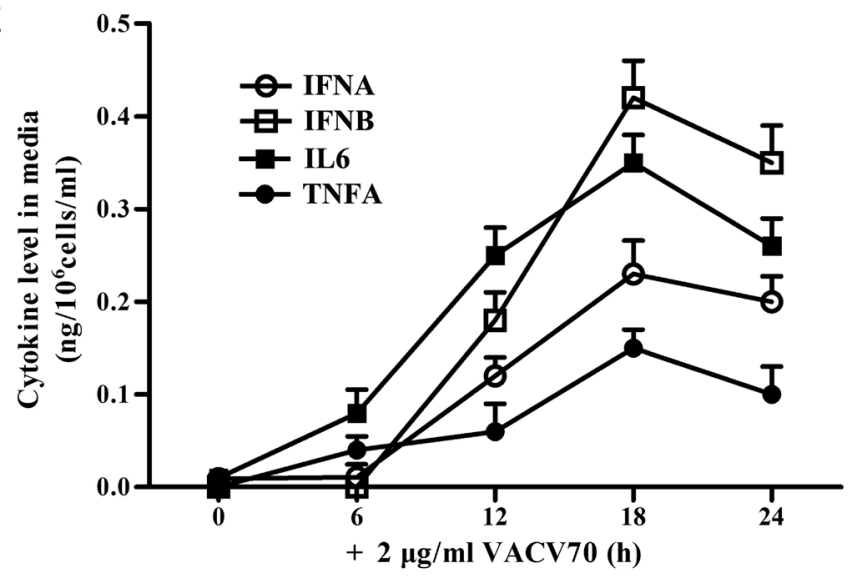

Figure $2 \mathrm{VACV} 70$-induced innate immune responses. (A) P204 and cGas upregulation. Granulosa cells were transfected with VACV70 for specific durations. The relative mRNA levels of $p 204$ and cGas were determined by real-time quantitative RT-PCR. (B) The granulosa cells were lysed $24 \mathrm{~h}$ after VACV70 transfection. The p204 and cGAS protein levels were determined by Western blot analysis. $\beta$-Actin was used as loading control. (C) Time-dependent cytokine expression. Total RNA was extracted from granulosa cells at the indicated time points after VACV70 transfection. The relative mRNA levels of Ifna, Ifnb, I/6 and Tnfa were determined using real-time quantitative RT-PCR by normalizing to $\beta$-actin. (D) VACV70 dose-dependent cytokine expression. Granulosa cells were transfected with specific doses of VACV70 for $6 \mathrm{~h}$. The relative Ifna, Ifnb, II6 and Tnfa mRNA levels were determined by real-time quantitative RT-PCR. (E) Cytokine secretion. Granulosa cells were transfected with VACV70 for the indicated durations. The IFNA, IFNB, IL6 and TNFA levels in the culture medium were measured using an ELISA. The Western blot images represent at least three independent experiments. The data are presented as the mean \pm S.E.M. of three independent experiments. ${ }^{*} P<0.05$. 
Enzyme-linked immunosorbent assay (ELISA) results showed that the protein levels of these cytokines in the culture medium were significantly increased (Fig. 2E). The peak levels were detected $18 \mathrm{~h}$ after VACV70 transfection.

Various antiviral proteins can be upregulated in response to viral infections (Diamond \& Farzan 2013). Major antiviral protein genes, including Oas 1, Mx 1 and Isg15, were dramatically induced by VACV70 in a timedependent manner (Fig. 3A). The highest mRNA levels were detected $16 \mathrm{~h}$ after VACV70 transfection. The upregulation of these antiviral proteins was confirmed at the protein level by Western blot analysis $24 \mathrm{~h}$ after VACV70 transfection (Fig. 3B).

\section{$N F-\kappa B$ and IRF3 activation}

Given that cytosolic DNA sensor signaling can induce both IL6/TNFA expression via NF- $\mathrm{kB}$ activation and type I IFN expression via IRF3 activation (Unterholzner et al. 2010), we examined NF-KB and IRF3 activation in granulosa cells after VACV70 transfection. The Western blot results showed that VACV70 induced NF-KB and IRF3 phosphorylation in a time-dependent manner (Fig. 4A). The expression of phospho (p)-p65 (Ser536) and p-IRF3 (Ser396) was detected $1 \mathrm{~h}$ after VACV70 transfection, peaked at $2 \mathrm{~h}$ and declined at $3 \mathrm{~h}$. In the control cells, adding transfection reagent alone to the medium for $2 \mathrm{~h}$ did not induce the phosphorylation of

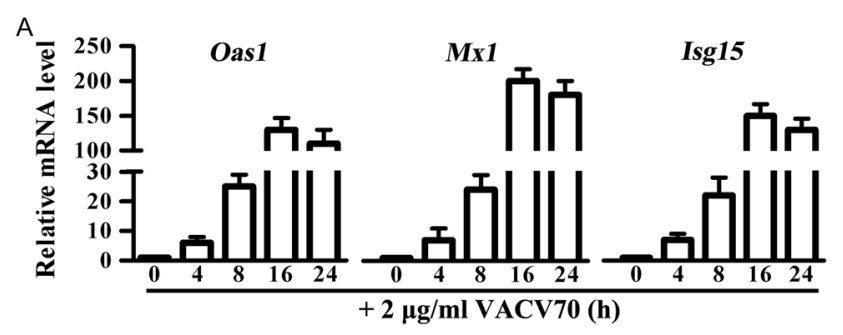

B

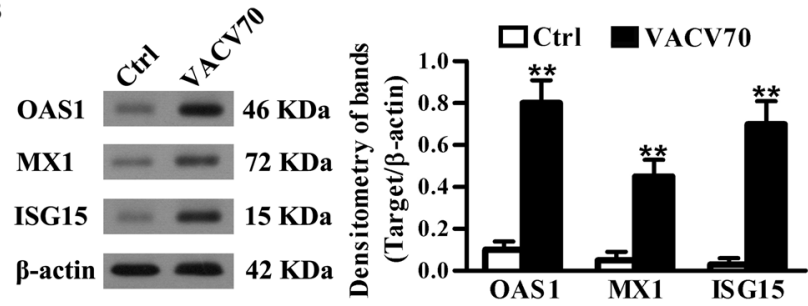

Figure 3 Expression of antiviral proteins. (A) RNA levels. Total RNA was extracted from granulosa cells at specific time points after transfection with VACV70. The relative mRNA levels of Oas 1, Mx1 and $\operatorname{lsg} 15$ were examined using real-time quantitative RT-PCR. (B) Protein levels. Granulosa cells were transfected with VACV70. After $24 \mathrm{~h}$, the cell lysates were subjected to Western blot analysis to probe antiviral proteins using specific antibodies. Cells treated with Lipofectamine RNAiMAX alone served as Ctrl. $\beta$-Actin was used as the loading control. The images are representative of at least three independent experiments. The data are presented as the mean \pm S.E.M. of three independent experiments. ${ }^{* *} P<0.01$.
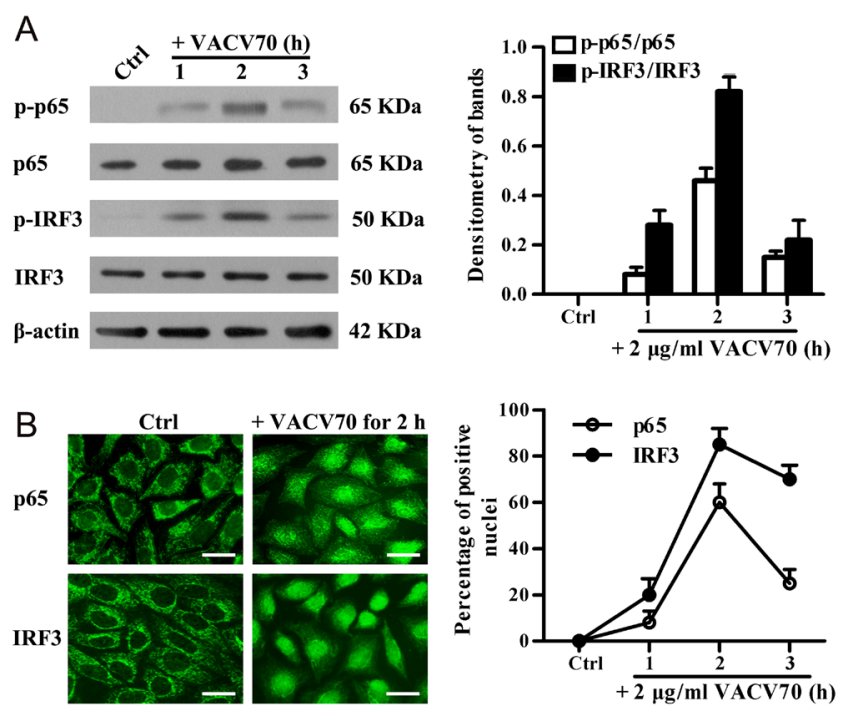

Figure 4 Activation of interferon regulatory factor 3 (IRF3) and nuclear factor kappa B (NF-kB). (A) Phosphorylation of NF-kBp65 (p65) and IRF3. Granulosa cells were transfected with VACV70 for the specified durations. Cells that were transfected with Lipofectamine RNAiMAX alone for $2 \mathrm{~h}$ served as Ctrl. The cell lysates were analyzed via Western blot using specific antibodies against phospho-p65 (p-p65), p65, phospho-IRF3 and IRF3. $\beta$-Actin was used as the loading control. (B) Translocation of IRF3 and p65 from the cytoplasm to the nucleus. Granulosa cells were treated as in (A). The cellular distributions of IRF3 and p65 were determined by

immunofluorescence staining using specific antibodies. The dynamics of IRF3 and p65 nuclear translocation were quantitatively analyzed by counting 300 cells at the indicated time points after VACV70 transfection (right panel). The images are representative of three separate experiments. The data represent the mean \pm S.E.M. of three experiments. Bar $=20 \mu \mathrm{m}$.

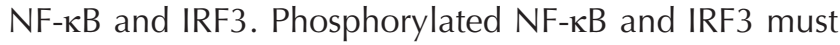
translocate into nuclei to induce cytokine expression. Immunofluorescence staining showed that NF- $\mathrm{kB}$ and IRF3 efficiently translocated into the cell nuclei in a time-dependent manner (Fig. 4B). Peak levels of nuclear translocation were observed $2 \mathrm{~h}$ after transfection, corresponding with the timing of peak phosphorylation efficiencies. In the control cells, the transfection reagent alone did not induce the nuclear translocation of NF- $\mathrm{kB}$ and IRF3.

To clarify the involvement of NF- $\mathrm{\kappa B}$ and IRF3 activation in the VACV70-induced innate immune response in ovarian granulosa cells, the signaling pathways that are responsible for VACV70-induced gene expression were examined. VACV70-induced phosphorylation of NF- $\mathrm{KB}$ and IRF3 in granulosa cells was efficiently blocked by pre-incubating the cells with the appropriate inhibitors $(10 \mu \mathrm{M}$ BAY11-7082 for NF- $\mathrm{kB}$ activation and $1 \mu \mathrm{g} / \mathrm{mL}$ BX795 for IRF3 activation) (Fig. 5A). A 2-h pretreatment with the inhibitors differentially decreased the VACV70-induced TNFA, IL6 and IFNA/B secretion into the culture medium (Fig. 5B). BAY11-7082 significantly decreased VACV70-induced TNFA and IL6 levels; 

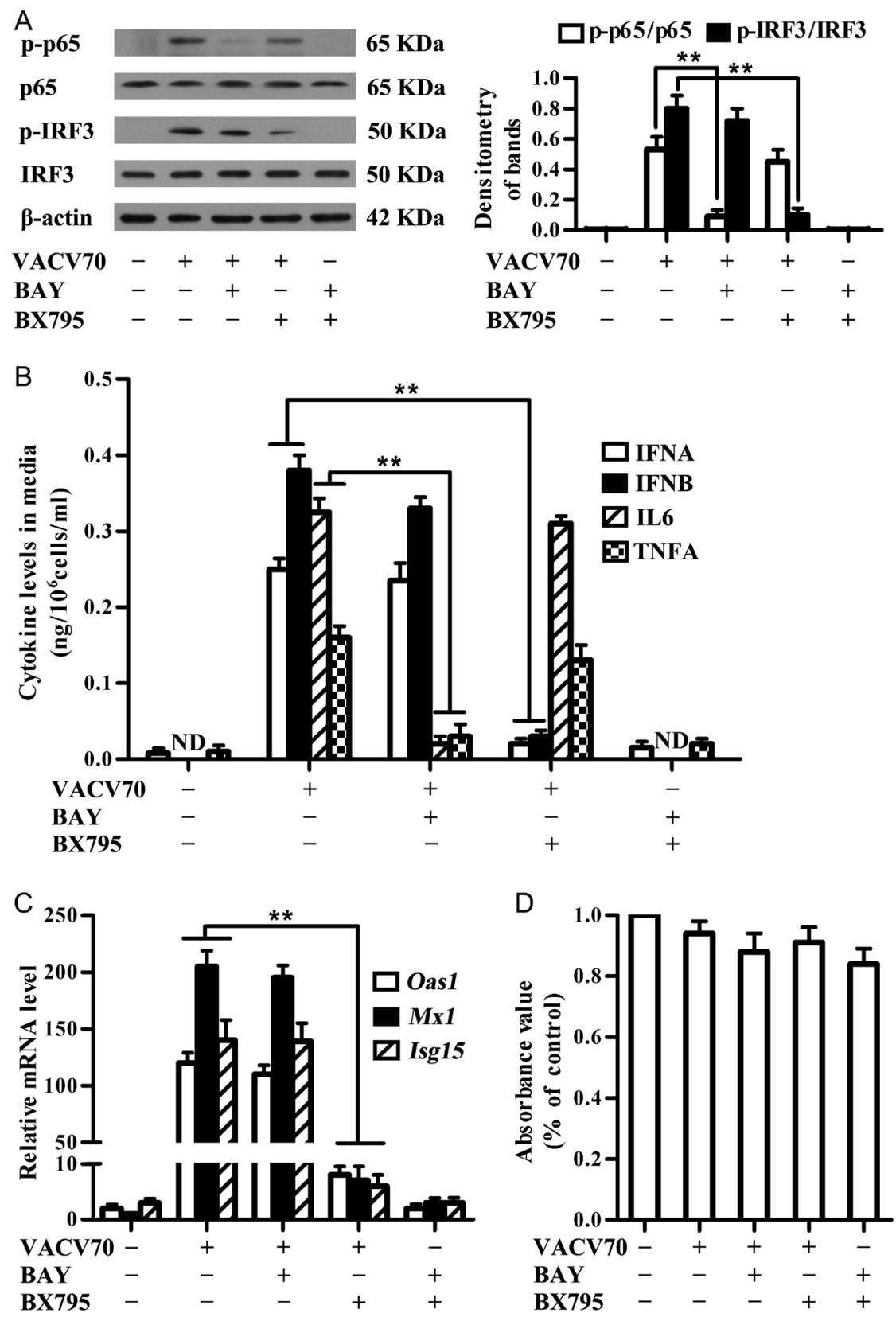

Figure 5 Involvement of NF-kB and IRF3 activation in VACV70-induced gene expression. (A) Inhibition of NF-kB and IRF3 activation by appropriate inhibitors. Granulosa cells were transfected with $2 \mu \mathrm{g} / \mathrm{mL}$ VACV70 alone or after $2 \mathrm{~h}$ of pre-incubation with inhibitors $(10 \mu \mathrm{M}$ BAY11-7082 (BAY) for NF- $\mathrm{KB}, 1 \mu \mathrm{g} / \mathrm{mL}$ BX795 for IRF3). At $2 \mathrm{~h}$ after transfection, the cell lysates were subjected to Western blot analysis using specific antibodies to probe the indicated proteins. (B) Secretion of cytokines. Granulosa cells were cultured in 6 -well plates at a density of $5 \times 10^{5}$ cells/well and treated as in (A). At $18 \mathrm{~h}$ after transfection, the cytokine concentrations in the culture medium were measured by ELISA. ND, not detectable. (C) Expression of antiviral proteins. Granulosa cells were treated as in (A) for $16 \mathrm{~h}$. The relative mRNA levels of Oas 1, Mx1 and Isg15 were determined using real-time quantitative RT-PCR. (D) Cell viability. Granulosa cells were treated as in (A) for $18 \mathrm{~h}$. After treatment with MTT assay agents, the cells were lysed, and the absorbance at $570 \mathrm{~nm}$ was recorded. The images are representative of at least three experiments. The data represent the mean \pm S.E.M. of three experiments. ${ }^{* *} P<0.01$.

however, it did not affect the IFNA/B secretion. By contrast, BX795 markedly inhibited the secretion of IFNA/B and did not affect TNFA and IL6 expression. Moreover, the VACV70-induced upregulation of Oas1, Mx1 and Isg15 was significantly inhibited by BX795 but not by BAY11-7082 (Fig. 5C). In the control cells, the inhibitors did not affect cytokine production or antiviral protein expression in basal conditions. The MTT assay results showed that the cell viability was not significantly affected by VACV70 or the chemical inhibitors (Fig. 5D). These results imply that VACV70 induces TNFA and IL6 expression through NF-KB activation and induces the expression of IFNA/B and antiviral proteins by IRF3 activation.

\section{Involvement of p204 and cGAS signaling}

P204 and cGAS initiate innate immune responses through the adaptor STING (Ishikawa et al. 2009). To further verify the involvement of p204 and cGAS signaling in the VACV70-induced antiviral response, we examined the effect of VACV70 after the individual knockdown of p204, cGas and Sting in granulosa cells using specific small-interfering RNAs (siRNAs). Each siRNA inhibited $>70 \%$ of the target mRNA $24 \mathrm{~h}$ after transfection (Fig. 6A). Accordingly, the protein levels of p204, cGAS and STING were significantly reduced by siRNA (Fig. 6B). As a control, a siRNA targeting a scrambled sequence (siCtrl) had no effect on p204, cGAS 
and STING expression. At $24 \mathrm{~h}$ after siRNA transfection, the cells were then transfected with VACV70. The pretreatment of cells with siRNAs targeting p204 (sip204), cGas (sicGas) or Sting (siSting) significantly inhibited p-IRF3 (Ser396) and p-p65 (Ser536) levels at $2 \mathrm{~h}$ after VACV70 transfection (Fig. 6C). The secretion of cytokines was significantly inhibited when the cells were pretreated with sip204, sicGas or siSting compared with siCtrl at $18 \mathrm{~h}$ after VACV70 transfection (Fig. 6D). Moreover, the antiviral protein levels were also dramatically reduced by sip204, sicGas or siSting (Fig. 6E). Notably, the knockdown of p204 and cGAS had comparable inhibitory effects on the VACV70-induced innate immune response. However, the knockdown of STING resulted in a more severe inhibition compared with p204 and cGAS silencing. Cell viability was insignificantly affected by siRNA transfection (Fig. 6F).

\section{VACV70 inhibits P450 aromatase expression in ovarian granulosa cells}

Many studies have demonstrated that inflammatory factors, especially TNFA, can inhibit estradiol synthesis in granulosa cells (Morales et al. 2006, Yan et al. 2013, 2014 , 2015). To further confirm the impact of VACV70induced TNFA production on the expression of P450 aromatase (P450arom), which is the key enzyme for estradiol synthesis in granulosa cells, we examined P450arom expression in different conditions. VACV70 markedly inhibited the mRNA level of P450arom in a time-dependent (Fig. 7A) and dose-dependent (Fig. 7B) manner. The lowest mRNA level in granulosa cells was detected at $16 \mathrm{~h}$ after VACV70 transfection. Both 2 and $5 \mu \mathrm{g} / \mathrm{mL}$ VACV70 significantly suppressed P450arom expression. Notably, the VACV70-mediated inhibition of P450arom expression was significantly reversed by the presence of AnTNFA, the TNFA-neutralizing antibody that can neutralize the cytotoxic activity of mouse TNFA (Fig. 7C). An MTT assay showed that VACV70 and AnTNFA did not affect granulosa cell survival at $24 \mathrm{~h}$ after treatment (Fig. 7D). Accordingly, the protein level of P450arom was also markedly inhibited by VACV70 transfection, and this inhibition was significantly reversed by adding AnTNFA to the medium (Fig. 7E). Furthermore, the estradiol secretion in media was similar to the expression of P450arom. VACV70 transfection
A

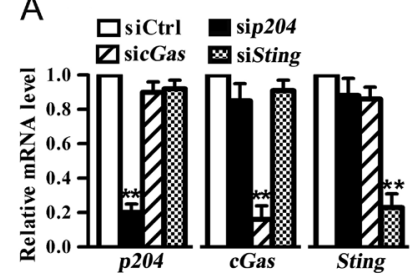

C

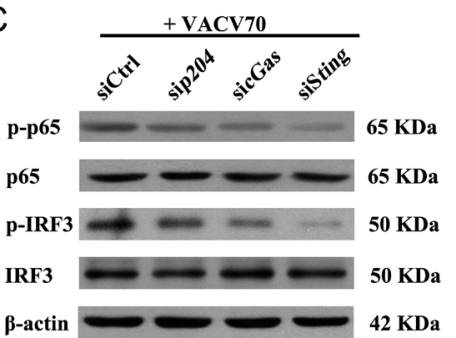

E
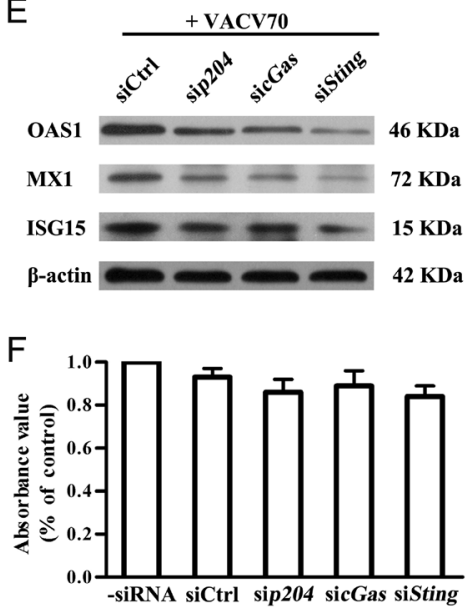

B
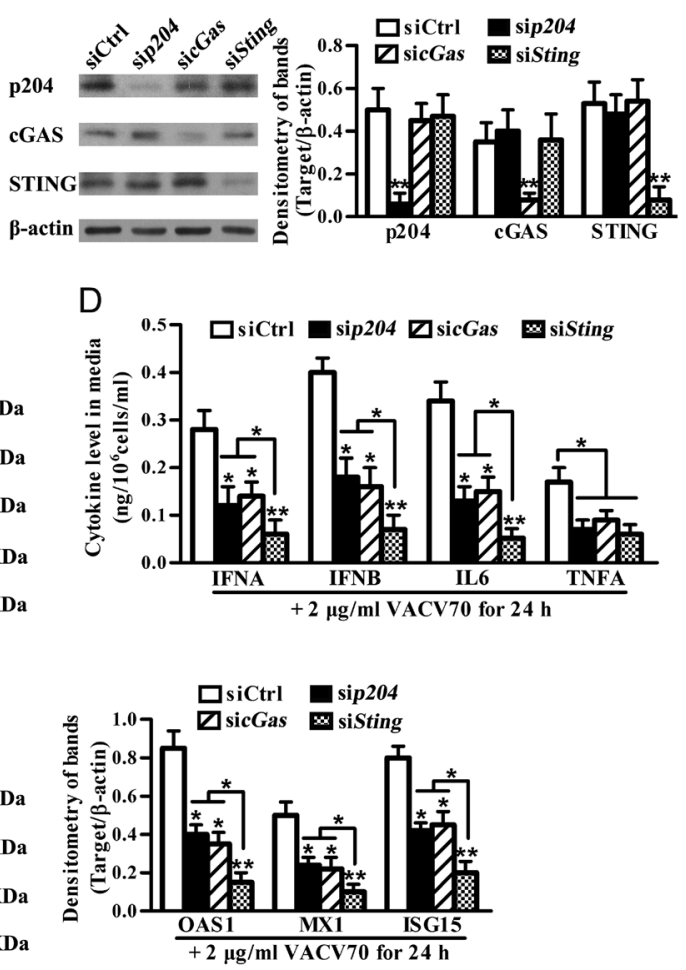

www.reproduction-online.org
Figure 6 Roles of DNA sensors in VACV70induced innate immune responses. (A and B) Knockdown of p204, cGAS and STING using specific siRNAs. Granulosa cells were transfected with individual siRNAs that targeted a scrambled sequence (siCtrl), p204 (sip204), cGas (sicGas) or Sting (siSting). After $24 \mathrm{~h}$, the p204, cGAS and STING expression levels were determined using real-time quantitative RT-PCR (A) and Western blot analysis (B). (C) NF- $\mathrm{kB}$ and IRF3 activation. Granulosa cells were transfected with the indicated siRNAs. Twenty-four hours later, the cells were transfected with VACV70. At $2 \mathrm{~h}$ after transfection, the cell lysates were subjected to Western blot analysis using specific antibodies to probe the indicated proteins. (D) Cytokine secretion. Granulosa cells were treated as in (C). At $18 \mathrm{~h}$ after VACV70 transfection, the cytokine levels in the culture medium were measured by an ELISA. (E) Antiviral protein expression. Granulosa cells were treated as in (C). At $24 \mathrm{~h}$ after VACV70 transfection, antiviral protein levels were determined by Western blot analysis. (F) Cell viability. Granulosa cells were treated as in (C). At 24h after VACV70 transfection, the cells were lysed after treatment with MTT assay agents. The absorbance at $570 \mathrm{~nm}$ was recorded. The images are representative of at least three independent experiments. The data represent the mean \pm S.E.M. Of three independent experiments. ${ }^{*} P<0.05,{ }^{*} P<0.01$. 

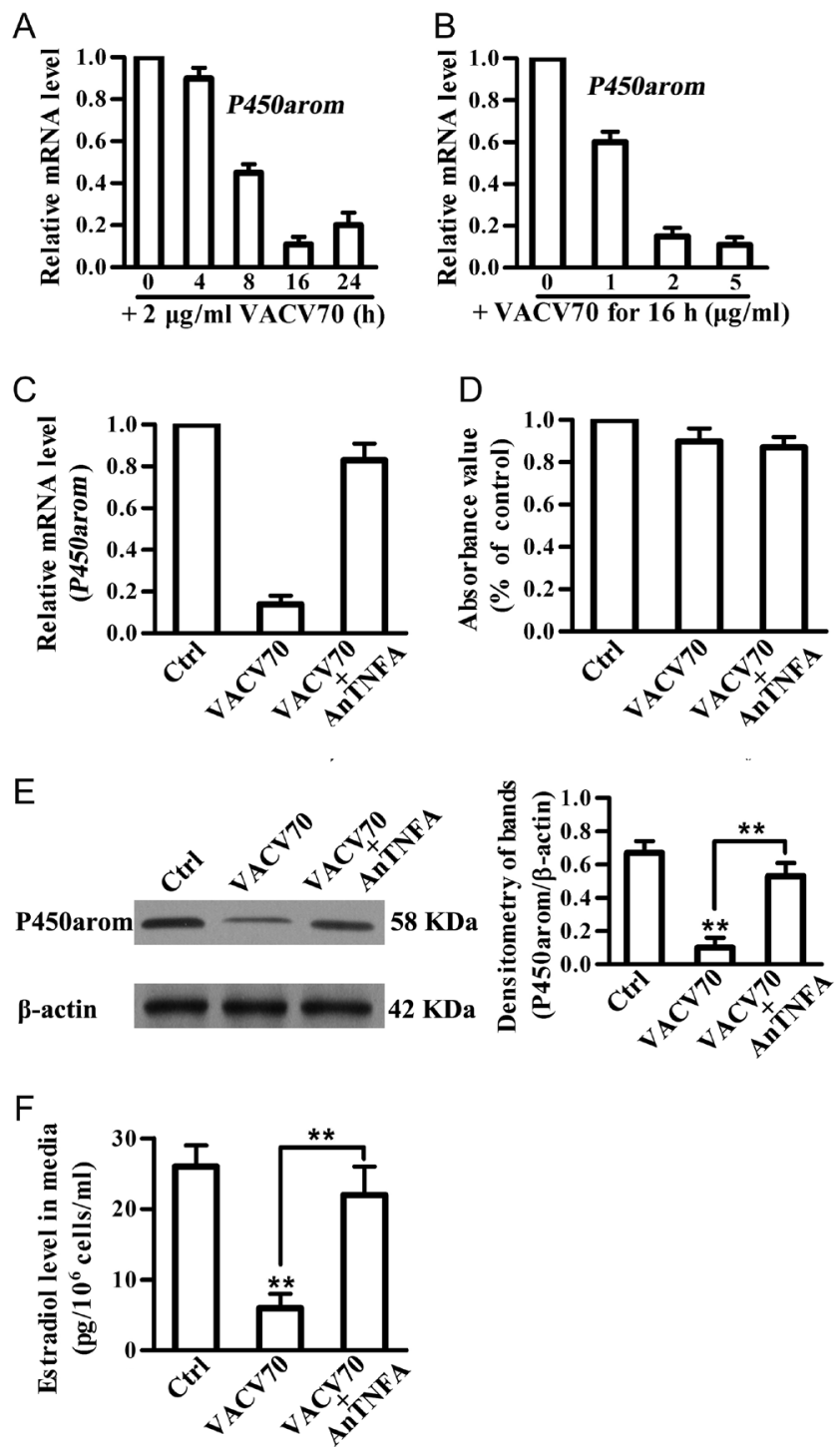

Figure 7 Inhibition of P450arom expression. (A and B) VACV70 inhibited P450arom expression. Granulosa cells were seeded in 6 -well plates at a density of $2 \times 10^{5}$ cells/well. After $24 \mathrm{~h}$, the cells were transfected with VACV70. The effect of VACV70 on P450arom expression in a time-dependent (A) and dose-dependent (B) manner was examined using real-time quantitative RT-PCR by normalizing to $\beta$-actin. (C) Granulosa cells were seeded as in A and B. After $24 \mathrm{~h}$, the cells were transfected with $2 \mu \mathrm{g} / \mathrm{mL}$ VACV70 alone or VACV70 with $30 \mathrm{ng} / \mathrm{mL}$ AnTNFA. At $16 \mathrm{~h}$ after treatment, the total RNA was extracted, and the relative mRNA levels of P450arom were determined using real-time quantitative RT-PCR. Cells that were transfected with Lipofectamine RNAiMAX alone served as Ctrl. (D) Cell viability. Granulosa cells were treated as in (C). The cell viability was assessed using an MTT assay at $24 \mathrm{~h}$ after treatment. (E) Protein levels of P450arom. Granulosa cells were treated as in (C). At $24 \mathrm{~h}$ after treatment, the cell lysates were subjected to Western blot analysis using specific antibodies to P450arom. $\beta$-Actin was used as a loading control. (F) Estradiol secretion in media. Granulosa cells were treated as in (C). The culture media were subjected to ELISA to determine estradiol level at $24 \mathrm{~h}$ after treatment. The images are representative of at least three experiments. The data represent the mean \pm S.E.M. of three experiments. ${ }^{* *} P<0.01$. significantly inhibited estradiol secretion, and this inhibition was reduced by AnTNFA (Fig. 7F).

\section{VACV70 induces the ovarian innate immune response and suppresses steroidogenesis in vivo}

To confirm the effect of VACV70 in vivo, a mixture of VACV70 and Lipofectamine RNAimax was locally injected into the ovarian bursa of one ovary. Noticeably increased p-p65 (Ser536) and p-IRF3 (Ser396) levels were detected at $3 \mathrm{~h}$ after VACV70 injection (Fig. 8A). In the contralateral ovary, the injection of Lipofectamine RNAimax alone did not induce p65 and IRF3 phosphorylation. We further examined the expression of cytokines and antiviral proteins in vivo. At $24 \mathrm{~h}$ after VACV70 injection, the levels of IFNA, IFNB, IL6 and TNFA in the ovary lysates were significantly increased (Fig. 8B). The expression of antiviral proteins was also dramatically upregulated by VACV70 injection (Fig. 8C). Furthermore, the mRNA levels of steroidogenic enzymes, including P450arom, cytochrome P450 sidechain cleavage enzyme (P450SCC), 3 $\beta$-hydroxysteroid dehydrogenase $(\mathrm{Hsd} 3 \mathrm{~b})$ and steroidogenic acute regulatory protein (Star), were evidently reduced at $24 \mathrm{~h}$ after VACV70 injection (Fig. 8D). The Western blot results showed that all these steroidogenic enzymes were significantly inhibited by VACV70 injection at the protein levels (Fig. 8E). Correspondingly, the ovarian estradiol and testosterone levels were evidently decreased at $24 \mathrm{~h}$ after VACV70 injection (Fig. 8F and G).

\section{Discussion}

Various viruses, including RNA and DNA viruses, can infect the ovary and affect ovarian functions (Zhao et al. 2011, Wang et al. 2016). Understanding the mechanisms underlying innate immune responses in the ovary can aid in the development of therapeutic and preventive approaches against viral infections. We recently demonstrated that viral RNA sensors initiate innate immune responses in the mouse ovary, which impair ovarian functions (Yan et al. 2013, 2014, 2015, Wang et al. 2016). The present study examined the cytosolic DNA sensor-initiated innate immune responses in mouse granulosa cells and their effects on the endocrine function.

In comparison with peritoneal macrophages, we demonstrated that granulosa cells constitutively express p204, cGAS and the signaling adaptor STING. By contrast, DAI and Pol III were not evidently detected in granulosa cells. P204 is located in both the cytoplasm and nuclei of granulosa cells. This cellular distribution corresponds to the previous observation in other cells and is conveniently modulated by protein acetylation ( $\mathrm{Li}$ et al. 2012). VACV70 can trigger the innate immune response after transfection into cells (Unterholzner et al. 2010). 
A

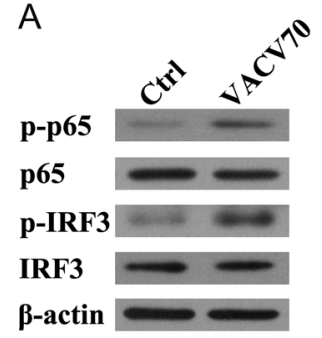

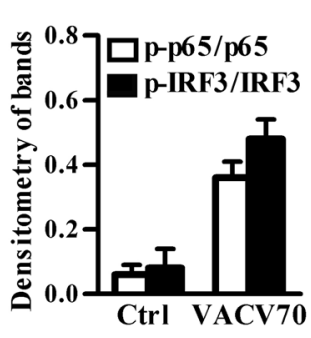

B

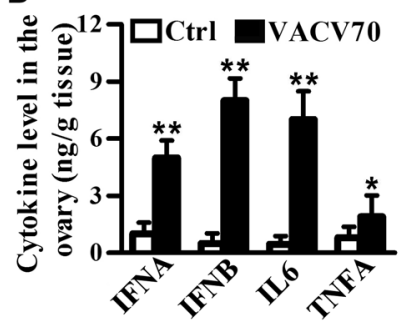

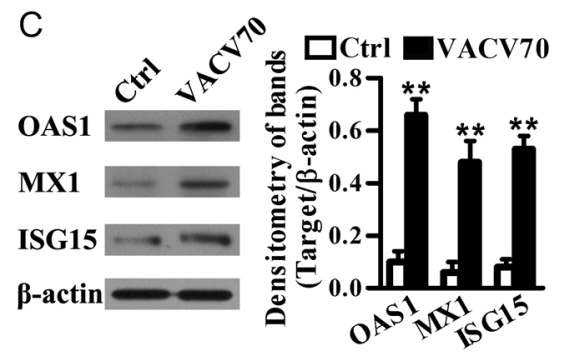

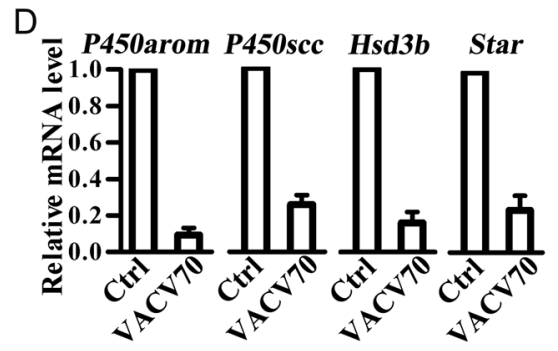

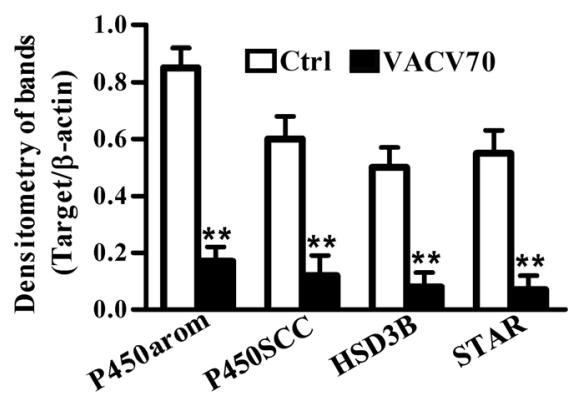

G

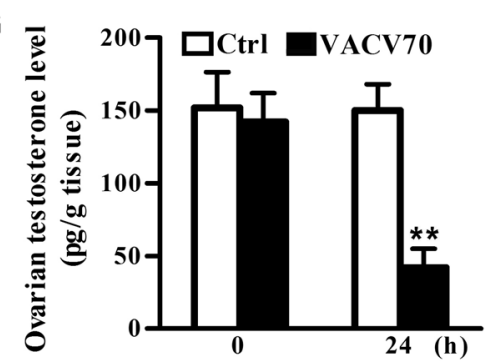

Figure 8 The VACV70-induced ovarian innate immune responses in vivo. (A) NF- $\mathrm{\kappa B}$ and IRF3 activation. A mixture of VACV70 and

Lipofectamine RNAiMAX was injected into the ovarian bursa of one ovary, and the contralateral ovary was injected with Lipofectamine RNAiMAX alone as Ctrl. At $3 \mathrm{~h}$ after injection, the ovary lysates were analyzed via Western blot using specific antibodies to probe the indicated proteins. (B) Cytokine levels. At $24 \mathrm{~h}$ after injection, the levels of cytokines in the ovarian lysates were measured by ELISA. (C) Expression of antiviral proteins. At $24 \mathrm{~h}$ after injection, the ovarian lysates were subjected to Western blot analysis to probe the antiviral proteins using specific antibodies. (D and E) Inhibition of steroidogenic enzymes. At $24 \mathrm{~h}$ after injection, the mRNA (D) and protein (E) levels of steroidogenic enzymes were examined by real-time quantitative RT-PCR and Western blot respectively. (F and G) Inhibition of estradiol and testosterone synthesis. At 0 and $24 \mathrm{~h}$ after VACV70 injection, the levels of estradiol (F) and testosterone (G) in the ovarian lysates were measured by ELISA. The images are representative of at least three experiments. The ovarian lysates of three mice were used in each experiment. The data represent the mean \pm S.E.M. of three experiments. ${ }^{*} P<0.05,{ }^{*} P<0.01$.
P204 and cGAS were further upregulated by VACV70 in granulosa cells. The peak mRNA levels of p204 and cGas appeared later than the cytokines after VACV70 transfection. P204 and cGAS were constitutively expressed in granulosa cells under basal condition. These two DNA sensors can recognize transfected VACV70 and immediately induce the expression of cytokines. IFNB produced by granulosa cells can upregulate DNA sensors expression. The upregulation of DNA sensors may be a positive feedback to amplify innate immune responses. We provide evidence that both p204 and cGAS signaling pathways are involved in innate immune responses in granulosa cells. These results expand our recent observations that dsRNA sensors, including TLR3, MDA5 and RIG-I, initiate the antiviral response in the mouse ovary (Yan et al. 2013, 2014, 2015).
The doses of VACV70 used in previous studies are different from 0.5 to $5 \mu \mathrm{g} / \mathrm{mL}$ (Unterholzner et al. 2010). The present study found that $2 \mu \mathrm{g} / \mathrm{mL}$ VACV70 can strongly trigger cytosolic DNA sensor signaling in mouse ovarian granulosa cells. This dose has no relevance to natural virus titers because virus titers in natural infections can be different and natural viruses may replicate in hosts. Moreover, viral particles may activate multiple PRRs because viral components may activate other PRRs beyond DNA sensors. Therefore, as a synthetic DNA analog, VACV70 does not equate to infection of natural viruses.

Type I IFN production is a primary response of hosts to viral infection (Randall \& Goodbourn 2008). IFNA and IFNB play crucial roles in the antiviral activities by the upregulation of antiviral proteins and the promotion 
of adaptive immune responses against invading viruses (Katze et al. 2002). The current study demonstrated that major antiviral proteins, including OAS1, ISG15 and MX1, were dramatically upregulated by VACV70, which would favor the cellular defense against invading viruses. Given that all of these antiviral proteins are encoded by IFN-inducible genes (Sadler \& Williams 2008), it is reasonable to speculate that the VACV70mediated upregulation of the antiviral proteins could be attributed to the production of IFNA/B. Accordingly, the presence of BX795, an inhibitor of IRF3 activation, significantly decreased the VACV70-induced IFNA/B and antiviral protein production. The peak mRNA levels of the antiviral proteins appeared later than $/ f n a / b$ in granulosa cells after VACV70 transfection, suggesting that IFNA/B may induce the antiviral protein expression in an autocrine manner.

The results of the present study indicate that VACV70 also induced TNFA and IL6 production via NF-KB activation in granulosa cells. In contrast, our other recent studies demonstrated that DNA sensor signaling does not induce TNFA and IL6 production in Leydig and adipose cells (Zhu et al. 2014, Yu et al. 2015). These results imply that various viruses may trigger different signaling pathways in different types of cells.

Steroidogenesis is one of the major functions of the ovary. Estradiol is synthesized by granulosa cells through the aromatization of androgens secreted by theca cells (Berisha et al. 2002). Multiple steroidogenic enzymes are required for the synthesis of estradiol and androgen, including P450arom, P450SCC, HSD3B and STAR. The present study demonstrated that not only the expression of these steroidogenic enzymes but also the secretion of estradiol and testosterone were inhibited by VACV70.

IFNA/B plays critical roles in the defense against viruses, whereas elevated levels of pro-inflammatory cytokines may perturb tissue functions. High levels of pro-inflammatory cytokines may result in pathological conditions, such as ovarian cancer (Maccio \& Madeddu 2012). Moreover, TNFA inhibits estradiol synthesis and induces granulosa cell apoptosis in rat ovaries (Kaipia et al. 1996, Morales et al. 2006, Yamamoto et al. 2015). TNFA also inhibits androgen synthesis in Leydig cells (Bornstein et al. 2004, Hong et al. 2004). Our previous study demonstrated that TNFA inhibits P450arom expression in granulosa cells in a dose-dependent manner. We speculated that the VACV70-mediated inhibition of estradiol synthesis could be attributed to TNFA production. In agreement with this speculation, we showed that TNFA-neutralizing antibodies significantly reversed the VACV70-mediated inhibition of estradiol synthesis in granulosa cells.

The theca cells express androgen synthetic enzymes and produce androgen (Berisha et al. 2002). Our data showed that the theca cells did not express cytosolic

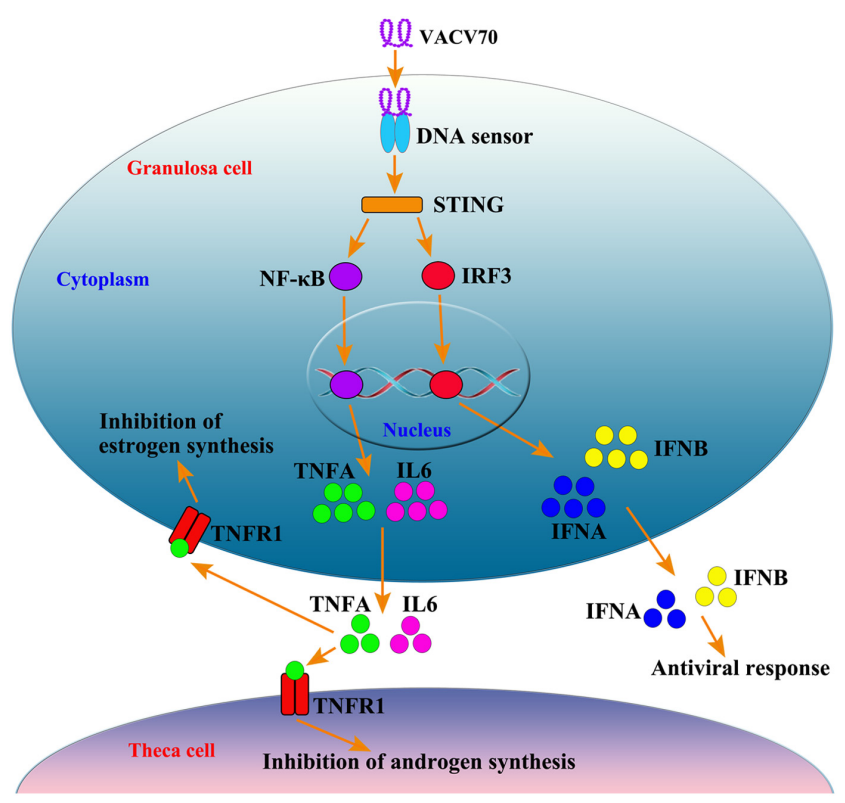

Figure 9 Summary picture. VACV70 transfection can trigger DNA sensor-STING signaling and induce the expression of inflammatory cytokines (TNFA/IL6) and type I interferons (IFNA/B) through NF- $\mathrm{kB}$ and IRF3 activation respectively. Type I interferons initiate antiviral responses by inducing antiviral proteins and facilitating antiviral adaptive immunity. The inflammatory cytokines, especially TNFA, can inhibit estrogen synthesis in granulosa cells and androgen synthesis in theca cells.

DNA sensors. Therefore, we speculated that theca cells do not directly response to VACV70. However, VACV70 significantly inhibited androgen synthesis and relevant steroidogenic enzymes expression. These effects could be mediated by inflammatory cytokines. In particular, increased TNFA level perturbs steroidogenesis in the theca cells (Bornstein et al. 2004). In agreement with this, we found that the theca cells abundantly express TNFA receptor 1 (TNFR1) (Yan et al. 2015). Therefore, we hypothesized that TNFA produced by ovarian granulosa cells could inhibit steroidogenesis in the theca cells.

In conclusion, we demonstrated that VACV70 initiates innate immune responses in mouse granulosa cells via cytosolic DNA sensor signaling (Fig. 9), which would contribute to the defense against DNA viral infection in the ovary. Moreover, the DNA sensor-initiated innate immune responses inhibit the steroidogenesis of the ovary. These data provide novel clues into the mechanism underlying the innate immune responses in the ovary to vaccinia viral infection.

\section{Declaration of interest}

The authors declare that there is no conflict of interest that could be perceived as prejudicing the impartiality of the research reported. 


\section{Funding}

This work was supported by the National Natural Science Foundation of China (Grant Nos. 81372777 and 81372779).

\section{References}

Barbalat R, Ewald SE, Mouchess ML \& Barton GM 2011 Nucleic acid recognition by the innate immune system. Annual Review of Immunology 29 185-214. (doi:10.1146/annurev-immunol-031210-101340)

Berisha B, Pfaffl MW \& Schams D 2002 Expression of estrogen and progesterone receptors in the bovine ovary during estrous cycle and pregnancy. Endocrine 17 207-214. (doi:10.1385/ENDO:17:3:207)

Bornstein SR, Rutkowski H \& Vrezas I 2004 Cytokines and steroidogenesis. Molecular and Cellular Endocrinology 215 135-141. (doi:10.1016/j. mce.2003.11.022)

Bromfield JJ \& Sheldon IM 2011 Lipopolysaccharide initiates inflammation in bovine granulosa cells via the TLR4 pathway and perturbs oocyte meiotic progression in vitro. Endocrinology 152 5029-5040. (doi:10.1210/en.2011-1124)

Camp TA, Rahal JO \& Mayo KE 1991 Cellular localization and hormonal regulation of follicle-stimulating hormone and luteinizing hormone receptor messenger RNAs in the rat ovary. Molecular Endocrinology 5 1405-1417. (doi:10.1210/mend-5-10-1405)

Cejtin HE, Kalinowski A, Bacchetti P, Taylor RN, Watts DH, Kim S, Massad LS, Preston-Martin S, Anastos K, Moxley M et al. 2006 Effects of human immunodeficiency virus on protracted amenorrhea and ovarian dysfunction. Obstetrics and Gynecology 108 1423-1431. (doi:10.1097/01.AOG.0000245442.29969.5c)

Chiu YH, Macmillan JB \& Chen ZJ 2009 RNA polymerase III detects cytosolic DNA and induces type I interferons through the RIG-I pathway. Cell 138 576-591. (doi:10.1016/j.cell.2009.06.015)

Chong MM, Metcalf D, Jamieson E, Alexander WS \& Kay TW 2005 Suppressor of cytokine signaling- 1 in T cells and macrophages is critical for preventing lethal inflammation. Blood 106 1668-1675. (doi:10.1182/ blood-2004-08-3049)

Desmet CJ \& Ishii KJ 2012 Nucleic acid sensing at the interface between innate and adaptive immunity in vaccination. Nature Reviews Immunology 12 479-491. (doi:10.1038/nri3247)

Diamond MS \& Farzan M 2013 The broad-spectrum antiviral functions of IFIT and IFITM proteins. Nature Reviews Immunology 13 46-57. (doi:10.1038/nri3344)

Fu G, Chen C, Huang Y, Cheng L, Fu Q, Wan C, Shi S, Chen H \& Liu W 2016 Comparative analysis of transcriptional profiles of retinoic-acidinduced gene I-like receptors and interferons in seven tissues from ducks infected with avian Tembusu virus. Archives of Virology 161 11-18. (doi:10.1007/s00705-015-2621-x)

Herath S, Williams EJ, Lilly ST, Gilbert RO, Dobson H, Bryant CE \& Sheldon IM 2007 Ovarian follicular cells have innate immune capabilities that modulate their endocrine function. Reproduction 134 683-693. (doi:10.1530/REP-07-0229)

Hong CY, Park JH, Ahn RS, Im SY, Choi HS, Soh J, Mellon SH \& Lee K 2004 Molecular mechanism of suppression of testicular steroidogenesis by proinflammatory cytokine tumor necrosis factor alpha. Molecular and Cellular Biology 24 2593-2604. (doi:10.1128/MCB.24.7.25932604.2004)

Hu XL, Zhou XP, Qian YL, Wu GY, Ye YH \& Zhu YM 2011 The presence and expression of the hepatitis B virus in human oocytes and embryos. Human Reproduction 26 1860-1867. (doi:10.1093/humrep/der103)

Hume DA, Halpin D, Charlton H \& Gordon S 1984 The mononuclear phagocyte system of the mouse defined by immunohistochemical localization of antigen F4/80: macrophages of endocrine organs. PNAS 81 4174-4177. (doi:10.1073/pnas.81.13.4174)

Ishikawa H, Ma Z \& Barber GN 2009 STING regulates intracellular DNA-mediated, type I interferon-dependent innate immunity. Nature 461 788-792. (doi:10.1038/nature08476)

Jin Y, Ye F, Shi J, Qiu H, Zhao Y, Lin S, Chen T, Liu M, He Y \& Zhang S 2011 Hepatitis B virus infection and replication in primary cultured human granulosa cells. Archives of Virology 156 1-7. (doi:10.1007/ s00705-010-0808-8)
Kaipia A, Chun SY, Eisenhauer K \& Hsueh AJ 1996 Tumor necrosis factoralpha and its second messenger, ceramide, stimulate apoptosis in cultured ovarian follicles. Endocrinology 137 4864-4870. (doi:10.1210/ endo.137.11.8895358)

Katze MG, He Y \& Gale M Jr 2002 Viruses and interferon: a fight for supremacy. Nature Reviews Immunology 2 675-687. (doi:10.1038/ nri888)

Keating SE, Baran M \& Bowie AG 2011 Cytosolic DNA sensors regulating type I interferon induction. Trends in Immunology 32 574-581. (doi:10.1016/j.it.2011.08.004)

Kumar H, Kawai T \& Akira S 2011 Pathogen recognition by the innate immune system. International Reviews of Immunology 30 16-34. (doi:10.3109/08830185.2010.529976)

Li M, Zhou Y, Feng G \& Su SB 2009 The critical role of Toll-like receptor signaling pathways in the induction and progression of autoimmune diseases. Current Molecular Medicine 9 365-374. (doi:10.2174/15665 2409787847137)

Li T, Diner BA, Chen J \& Cristea IM 2012 Acetylation modulates cellular distribution and DNA sensing ability of interferon-inducible protein IFI16. PNAS 109 10558-10563. (doi:10.1073/pnas.1203447109)

Liu Z, Shimada M \& Richards JS 2008 The involvement of the Toll-like receptor family in ovulation. Journal of Assisted Reproduction and Genetics 25 223-228. (doi:10.1007/s10815-008-9219-0)

Maccio A \& Madeddu C 2012 Inflammation and ovarian cancer. Cytokine 58 133-147. (doi:10.1016/j.cyto.2012.01.015)

Martinon F, Mayor A \& Tschopp J 2009 The inflammasomes: guardians of the body. Annual Review of Immunology 27 229-265. (doi:10.1146/ annurev.immunol.021908.132715)

McCart JA, Ward JM, Lee J, Hu Y, Alexander HR, Libutti SK, Moss B \& Bartlett DL 2001 Systemic cancer therapy with a tumor-selective vaccinia virus mutant lacking thymidine kinase and vaccinia growth factor genes. Cancer Research 61 8751-8757.

Medzhitov R 2007 Recognition of microorganisms and activation of the immune response. Nature 449 819-826. (doi:10.1038/ nature06246)

Morales V, Gonzalez-Robayna I, Santana MP, Hernandez I \& Fanjul LF 2006 Tumor necrosis factor-alpha activates transcription of inducible repressor form of $3^{\prime}, 5^{\prime}$-cyclic adenosine $5^{\prime}$-monophosphate-responsive element binding modulator and represses P450 aromatase and inhibin alpha-subunit expression in rat ovarian granulosa cells by a p44/42 mitogen-activated protein kinase-dependent mechanism. Endocrinology 147 5932-5939. (doi:10.1210/en.2006-0635)

Morrison JC, Givens JR, Wiser WL \& Fish SA 1975 Mumps oophoritis: a cause of premature menopause. Fertility and Sterility 26 655-659. (doi:10.1016/S0015-0282(16)41233-1)

Ohl J, Partisani M, Demangeat C, Binder-Foucard F, Nisand I \& Lang JM 2010 Alterations of ovarian reserve tests in Human Immunodeficiency Virus (HIV)-infected women. Gynécologie Obstétrique et Fertilité 38 313-317. (doi:10.1016/j.gyobfe.2009.07.019)

Orzalli MH \& Knipe DM 2014 Cellular sensing of viral DNA and viral evasion mechanisms. Annual Review of Microbiology 68 477-492. (doi:10.1146/annurev-micro-091313-103409)

Petrovska M, Dimitrov DG \& Michael SD 1996 Quantitative changes in macrophage distribution in normal mouse ovary over the course of the estrous cycle examined with an image analysis system. American Journal of Reproductive Immunology 36 175-183. (doi:10.1111/j.1600-0897.1996.tb00159.x)

Price JC, Cronin J \& Sheldon IM 2012 Toll-like receptor expression and function in the COV434 granulosa cell line. American Journal of Reproductive Immunology 68 205-217. (doi:10.1111/j.16000897.2011.01103.x)

Randall RE \& Goodbourn S 2008 Interferons and viruses: an interplay between induction, signalling, antiviral responses and virus countermeasures. Journal of General Virology 89 1-47. (doi:10.1099/ vir.0.83391-0)

Sadler AJ \& Williams BR 2008 Interferon-inducible antiviral effectors. Nature Reviews Immunology 8 559-568. (doi:10.1038/nri2314)

Serke H, Vilser C, Nowicki M, Hmeidan FA, Blumenauer V, Hummitzsch K, Losche A \& Spanel-Borowski K 2009 Granulosa cell subtypes respond by autophagy or cell death to oxLDL-dependent activation of the oxidized lipoprotein receptor 1 and toll-like 4 receptor. Autophagy 5 991-1003. (doi:10.4161/auto.5.7.9507) 
Sheldon IM \& Bromfield JJ 2011 Innate immunity in the human endometrium and ovary. American Journal of Reproductive Immunology 66 (Supplement 1) 63-71. (doi:10.1111/j.1600-0897.2011.01034.x)

Shimada M, Hernandez-Gonzalez I, Gonzalez-Robanya I \& Richards JS 2006 Induced expression of pattern recognition receptors in cumulus oocyte complexes: novel evidence for innate immune-like functions during ovulation. Molecular Endocrinology $203228-3239$. (doi:10.1210/ me.2006-0194)

Shimada M, Yanai Y, Okazaki T, Noma N, Kawashima I, Mori T \& Richards JS 2008 Hyaluronan fragments generated by sperm-secreted hyaluronidase stimulate cytokine/chemokine production via the TLR2 and TLR4 pathway in cumulus cells of ovulated COCs, which may enhance fertilization. Development 135 2001-2011. (doi:10.1242/ dev.020461)

Sun L, Wu J, Du F, Chen X \& Chen ZJ 2013 Cyclic GMP-AMP synthase is a cytosolic DNA sensor that activates the type I interferon pathway. Science 339 786-791. (doi:10.1126/science.1232458)

Takaoka A, Wang Z, Choi MK, Yanai H, Negishi H, Ban T, Lu Y, Miyagishi M, Kodama T, Honda K et al. 2007 DAI (DLM-1/ZBP1) is a cytosolic DNA sensor and an activator of innate immune response. Nature 448 501-505. (doi:10.1038/nature06013)

Unterholzner L, Keating SE, Baran M, Horan KA, Jensen SB, Sharma S, Sirois CM, Jin T, Latz E, Xiao TS et al. 2010 IFI16 is an innate immune sensor for intracellular DNA. Nature Immunology 11 997-1004. (doi:10.1038/ni.1932)

Vanderhyden BC, Telfer EE \& Eppig JJ 1992 Mouse oocytes promote proliferation of granulosa cells from preantral and antral follicles in vitro. Biology of Reproduction 46 1196-1204. (doi:10.1095/ biolreprod46.6.1196)

Veeranki S \& Choubey D 2012 Interferon-inducible p200-family protein IFI16, an innate immune sensor for cytosolic and nuclear doublestranded DNA: regulation of subcellular localization. Molecular Immunology 49 567-571. (doi:10.1016/j.molimm.2011.11.004)

Wang H, Chen Y, Ge Y, Ma P, Ma Q, Ma J, Xue S \& Han D 2005 Immunoexpression of Tyro 3 family receptors - Tyro 3, Axl, and Mer - and their ligand Gas6 in postnatal developing mouse testis. Journal of Histochemistry and Cytochemistry 53 1355-1364. (doi:10.1369/ jhc.5A6637.2005)

Wang Z, Choi MK, Ban T, Yanai H, Negishi H, Lu Y, Tamura T, Takaoka A, Nishikura K \& Taniguchi T 2008 Regulation of innate immune responses by DAI (DLM-1/ZBP1) and other DNA-sensing molecules. PNAS 105 5477-5482. (doi:10.1073/pnas.0801295105)

Wang Q, Wu H, Cheng L, Yan K, Shi L, Zhao X, Jiang Q, Wang F, Chen Y, Li Q \& Han D 2016 Mumps virus induces innate immune responses in mouse ovarian granulosa cells through the activation of Toll-like receptor 2 and retinoic acid-inducible gene I. Molecular and Cellular Endocrinology 436 183-194. (doi:10.1016/j.mce. 2016.07.033)

Woods DC, Schorey JS \& Johnson AL 2009 Toll-like receptor signaling in hen ovarian granulosa cells is dependent on stage of follicle maturation. Reproduction 137 987-996. (doi:10.1530/REP-08-0320)
Yamamoto Y, Kuwahara A, Taniguchi Y, Yamasaki M, Tanaka Y, Mukai Y, Yamashita M, Matsuzaki T, Yasui T \& Irahara M 2015 Tumor necrosis factor alpha inhibits ovulation and induces granulosa cell death in rat ovaries. Reproductive Medicine and Biology 14 107-115. (doi:10.1007/ s12522-014-0201-5)

Yan K, Zhu W, Yu L, Li N, Zhang X, Liu P, Chen Q, Chen Y \& Han D 2013 Toll-like receptor 3 and RIG-I-like receptor activation induces innate antiviral responses in mouse ovarian granulosa cells. Molecular and Cellular Endocrinology 372 73-85. (doi:10.1016/j. mce.2013.03.027)

Yan K, Liu P, Liu Z, Zhao S, Cheng L \& Han D 2014 Polyinosinicpolycytidylic acid initiates ovarian innate antiviral response and inhibits steroidogenesis in female mice. Biology of Reproduction 9011 (doi:10.1095/biolreprod.113.115360)

Yan K, Cheng L, Liu P, Liu Z, Zhao S, Zhu W, Wang Q, Wu H \& Han D 2015 Polyinosinic-polycytidylic acid perturbs ovarian functions through toll-like receptor 3-mediated tumor necrosis factor a production in female mice. Biology of Reproduction 93 11. (doi:10.1095/ biolreprod.115.128348)

Yoneyama M \& Fujita T 2007 Function of RIG-I-like receptors in antiviral innate immunity. Journal of Biological Chemistry 282 15315-15318. (doi:10.1074/jbc.R700007200)

Yu L, Liu P, Liu Z, Zhu W, Yan K, Chen Q \& Han D 2015 p204-mediated innate antiviral responses in mouse adipose cells and their effects on cell functions. Immunology and Cell Biology 93 147-157. (doi:10.1038/ icb.2014.83)

Zhang H, Zhang Y, Zhao H, Chen Q, Peng H, Lei L, Qiao J, Shi J, Cao Z, Duan E et al. 2013 Hormonal regulation of ovarian bursa fluid in mice and involvement of aquaporins. PLOS ONE 8 e63823. (doi:10.1371/ journal.pone.0063823)

Zhao Y, Adams YF \& Croft M 2011 Preferential replication of vaccinia virus in the ovaries is independent of immune regulation through IL-10 and TGF-beta. Viral Immunology 24 387-396. (doi:10.1089/ vim.2011.0020)

Zhou M, McFarland-Mancini MM, Funk HM, Husseinzadeh N, Mounajjed T \& Drew AF 2009 Toll-like receptor expression in normal ovary and ovarian tumors. Cancer Immunology, Immunotherapy $\mathbf{5 8}$ 1375-1385. (doi:10.1007/s00262-008-0650-y)

Zhu W, Liu P, Yu L, Chen Q, Liu Z, Yan K, Lee WM, Cheng CY \& Han D2014 p204-initiated innate antiviral response in mouse Leydig cells. Biology of Reproduction 91 8. (doi:10.1095/biolreprod.114.119396)

Received 18 December 2016

First decision 16 January 2017

Revised manuscript received 16 February 2017

Accepted 28 March 2017 